\title{
QUALITY IMPROVEMENT IN VIRTUAL HIGHER EDUCATION: A GROUNDED THEORY APPROACH
}

\author{
Rouhollah MAHDIUON \\ Department of Education \\ Azarbaijan Shahid Madani University \\ Tabriz, Iran \\ Davoud MASOUMI \\ Department of Education \\ University of Gavle, Gavle, Sweden \\ Maghsoud FARASATKHAH \\ Planning Department \\ Institute for Research and \\ Planning in Higher Education, Tehran, Iran
}

\begin{abstract}
The article aims to explore the attributes of quality and quality improvement including the process and specific actions associated with these attributes - that contribute enhancing quality in Iranian Virtual Higher Education (VHE) institutions. A total of 16 interviews were conducted with experts and key actors in Iranian virtual higher education. A constant comparative analysis was adopted to construct a grounded theory model. Drawing on the experiences and perspectives of key actors and experts closely associated with quality in e-learning, a paradigm model for quality improvement in virtual higher education institutions was developed. The model articulates causal conditions, action/interaction strategies, consequences, contextual factors and intervening environments. Interestingly, quality of learning, i.e. deep learning was the core phenomenon in quality of virtual higher education institutions.
\end{abstract}

Keywords: Quality improvement, e-learning, learning quality, grounded theory and virtual higher education.

\section{INTRODUCTION}

Information and communications technologies (ICT) increasingly impact and shape all aspects of our life, including the ways we learn and teach. The emergence of ICT-based initiatives in education as a driving force in the Knowledge Society is part of a wider context of change in higher education and society at large (Bhuasiri, Xaymoungkhoun, Zo, Rho and Ciganek, 2012).

In alignment with the growing demands for higher education, most of the higher education institutions across the world have adopted ICT as a way to response the increasing demands and enhance quality of teaching and learning process (Thurab-Nkhosi \& Marshall, 2009; Tucker \& Gentry, 2009). A large number of virtual institutions and e-universities have been established. In some of these institutions, all of the teaching, learning, communication and administration activities are conducted virtually -online or offline- as in University of Phoenix and in Open University of London. 
Similarly, higher education institutions in developing countries have significantly informed by Information Technology (IT). For instance, the number of virtual institutions (in this study virtual higher education institution assumed type of e- learning that included all of the universities and institutions that they attempt to take students virtually, at least in one or more undergraduate or graduate degree in education), programs and courses have considerably increased in developing countries (Allen, \& Seaman, 2013; Bhuasiri, Xaymoungkhoun, Zo, Rho and Ciganek, 2012; Liu, Liao, \& Pratt, 2009; Masoumi, 2010b; Sloan Consortium, 2010). The number of students enrolled in online (virtual) programs in Iran, as an instance, has enormously boosted in last six years from 4918 in 2007 to 19000 in 2011 (Iranian Higher Education Research and Planning Institute, 2012).

In an era of increased accountability and booming Virtual Higher Education Institutions, it is critical for authorities to be able to demonstrate that their approaches to e-learning as a mode of delivery for their institutions are sound and effective (Hosie, Schibeci, \& Backhaus, 2005; Oliver, 2005). In line with accountability movement in higher education (Oliver, 2005; Abdous, 2009; Masoumi \& Lindstrom, 2012), failures of a number of higher education institutions, such as UK e-University (Garrett, 2004) and the US Open University (Meyer, 2006), lack of appropriate tools and methods of quality control in e-learning (Ehlers, Hildebrandt, Gortz, and Pawlowski, 2005; Pawlowski, 2007), budget constraints (Abdous, 2009) and growing number of academic fraud cases, are pressuring higher education institutions to bring in and implement quality issues and measures in order to enhance educational practices and services.

However, quality is a value-laden and actor-relative (Harvey and Green, 1993; Dondi, Moretti, \& Nascimbeni, 2006; Jung and Latchem 2007), multi-dimensional (Giertz, 2001) and elusive (Green, 1994) concept. The quality in higher education have been patented with various concepts including Quality Assurance (QA), quality assessment, quality control, quality audit, quality management, and quality enhancement/improvement. Tacking each one of those concepts divers' interests and expectations of various internal and external actors in higher education institutions (Abdous, 2009). The different actors' interest and expectations can challenge not only the ways that quality can be taken into account but even the meaning of the quality. However, quality in higher education institutions are mostly characterized in terms of students' satisfactions, cost-effectiveness, and graduation rates (Jung, 2011).

Furthermore, quality in Iranian higher education has been faced with institutional and structural complications. For instance, there is no independent and non-governmental institutions to audit and assure quality in higher education as well as valid indicators, and standards which address the main actors' interests and expectations. On the other hand, imposing bureaucratic centralism in Iranian higher education have simplified the assessing and compering quality in Iranian higher education institutions, but it seems such approach have not made any significant contribution to quality of teaching and learning.

The growing concern with quality in e-learning has led higher education institutions to look for frameworks and approaches for managing quality (Inglis, 2005). Addressing these concerns, a large number of models, frameworks and guidelines have been developed for enhancing and assuring quality in e-learning (see Oliver, 2005; Reglin, 2006; Pawlowski, 2007; Abdous, 2009; Chen, 2009; Ireland and et al, 2009; Jung 2011; Masoumi \& Lindström, 2012; Ossiannilsson \& Landgren, 2012, Barat Dastjerdi, 2016). Adopting a positivistic approach, a number of these studies, models and frameworks have tried to extract factors that are shaping quality of e-learning. Applying such positivistic approach, however, may not meet the needs and expectations of Iranian virtual higher education institutions. Due to higher education institutions in Iran need to determine which process and specific actions 
can significantly contribute to quality enhancement regarding Iran's specific cultural contexts.

This study, thus, aims to develop a paradigm model to enhance quality in virtual institutions through examining key actors' perceptions about dimensions and consequences of quality in the context of the Iranian virtual higher education institutions. A systematic understanding of the quality from key actors' perspective i.e. scholars in the e-learning arena and virtual institutions' decision makers can contribute to create a framework for enhancing and assuring quality in VHE in the contexts of the developing counties.

\section{REVIEW OF E-QUALITY MODELS AND FRAMEWORKS}

Several models and frameworks have been developed for assuring and enhancing quality of e-learning (see Swedish National Agency for Higher Education, 2008; University of West Indies Distance Education Centre model, 2006; Australasian Council on Open, Distance and E-Learning, 2007; Council for Higher Education Accreditation, 2002; E-xcellence benchmarking model, 2006; Distance Education and Training Council, 2012; The SEEQUEL core quality framework, 2004). These models aimed to explore key factors in assuring and enhancing quality of e-learning. Key factors indicated in these studies and frameworks can be outlined in the following themes and/or factors: Technology, Pedagogy, Institution, Student support, Faculty support, Course development, Evaluation and Learning context. A brief picture of these factors is outlined in table 1.

Table 1. VHE quality dimensions based on literature

\begin{tabular}{ll}
\hline Dimensions & \multicolumn{1}{c}{ References } \\
\hline Technology & McKinnon, Walker \& Davis, 2000; Australasian Council on Open, Distance and E- \\
& Learning, 2007; Chen, 2009; Masoumi, 2010; Wu \& Lin, 2012; khan, 2005; \\
& Meier, Seufert \& Euler, 2012; Ossiannilsson \& Landgren, 2012; Fresen, 2007.
\end{tabular}

Pedagogy University of West Indies Distance Education Centre model, 2006; McKinnon, Walker \& Davis, 2000; Australasian Council on Open, Distance and E-Learning, 2007; Chen, 2009; The SEEQUEL core quality framework, 2004; Jung, 2011; Masoumi ,2010; Distance Education and Training Council, 2012; Wu \& Lin, 2012; khan, 2005; Jara \& Mellar, 2009; Meier, Seufert \& Euler, 2012; institute for higher education policy, 2000; Fresen, 2007.

Institution University of West Indies Distance Education Centre model, 2006; McKinnon, Walker \& Davis, 2000; Australasian Council on Open, Distance and E-Learning, 2007; Council for Higher Education Accreditation (CHEA), 2002; Chen, 2009; Elearning quality of Swedish National Agency for Higher Education, 2008; Excellence benchmarking model, 2006; Jung, 2011; Masoumi, 2010; Distance Education and Training Council, 2012; Wu \& Lin, 2012; khan, 2005; Meier, Seufert \& Euler, 2012; Ossiannilsson \& Landgren, 2012; institute for higher education policy, 2000; Fresen, 2007.

Student University of West Indies Distance Education Centre model, 2006; McKinnon, support Walker \& Davis, (2000); Australasian Council on Open, Distance and E-Learning, 2007; Council for Higher Education Accreditation (CHEA), 2002; Chen, 2009; Elearning quality of Swedish National Agency for Higher Education, 2008; Excellence benchmarking model, 2006; Jung, 2011; Masoumi, 2010; Distance Education and Training Council, 2012; Jara \& Mellar, 2009; institute for higher education policy, 2000; Fresen, 2007. 
Faculty support

Course development

Evaluation

Learning context

University of West Indies Distance Education Centre model, 2006; Australasian Council on Open, Distance and E-Learning, 2007; Council for Higher Education Accreditation (CHEA), 2002; Chen, 2009; E-learning quality of Swedish National Agency for Higher Education, 2008; E-xcellence benchmarking model, 2006; The SEEQUEL core quality framework, 2004; Jung, 2011; Masoumi, 2010; institute for higher education policy, 2000; Fresen, 2007.

University of West Indies Distance Education Centre model, 2006; Council for Higher Education Accreditation (CHEA), 2002; Chen, 2009; E-learning quality of Swedish National Agency for Higher Education, 2008; E-xcellence benchmarking model, 2006; The SEEQUEL core quality framework, 2004; Jung, 2011; Masoumi, 2010; Distance Education and Training Council, 2012; Wu \& Lin, 2012; khan, 2005; Jara \& Mellar, 2009; institute for higher education policy, 2000; Fresen, 2007.

University of West Indies Distance Education Centre model, 2006; E-learning quality of Swedish National Agency for Higher Education (2008); The SEEQUEL core quality framework, 2004; Jung, 2011; Masoumi, 2010; khan, 2005; Ossiannilsson \& Landgren, 2012; institute for higher education policy, 2000.

A number of these studies and frameworks approached quality of e-learning to provide a comprehensive model based on strategies, contextual and environmental factors (Masoumi, 2010). Lacking a comprehensive approach to quality in e-learning, the focus of a large number of the e-quality models and frameworks is, however, centered on a dimensional approach (Sultan \& Wong, 2013).

\section{METHODOLOGY}

\section{Method}

This study is focused on exploring the process of quality improvement among Iranian virtual higher education institutions. The research approach has been adopted from Strauss and Corbin's (1998) representation of Grounded Theory (GT). GT has been established as an appropriate and robust approach for carrying out qualitative research in which the purpose is to inductively generate theory in research (Brady \& Loonam, 2010). This approach provides a launching point to focus on key actors concerns in assessing and enhancing quality in VHU rather than imposing a preconceived research problem (Hoda Noble \& Marshall, 2011). Hence, this qualitative method seeks to discover perceptions, experiences and reactions of actors towards a concept, process, phenomenon, and action or interaction. Our rationale to use this research strategy is that there is a need for inductive theory development to explain how actors of virtual institutions are experiencing quality assurance and enhancement as a phenomenon (Creswell, 2012). To do so, following research process in practice were fulfilled (see figure 1). 


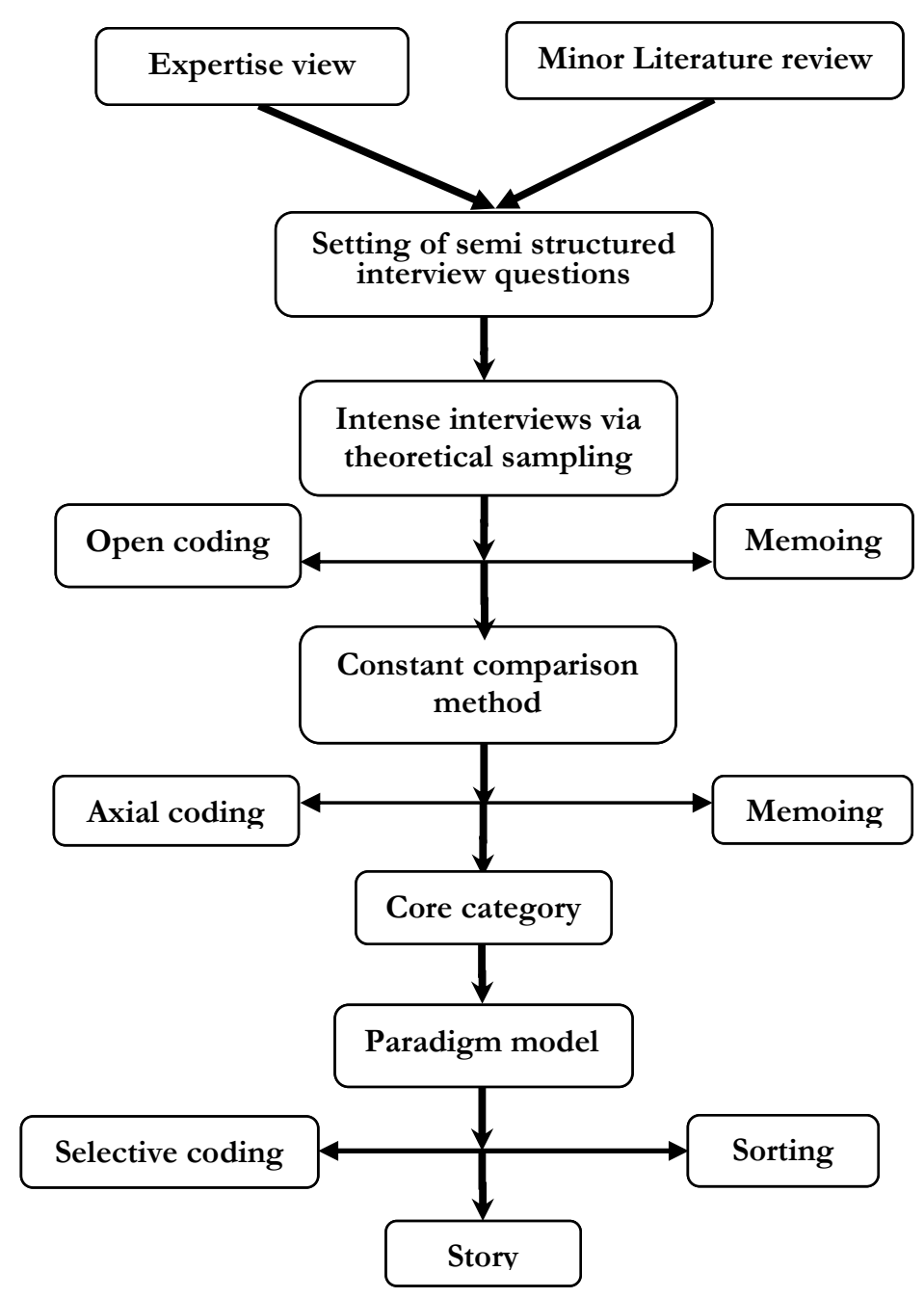

Figure 1. Research process in practice

\section{Data Collection}

The main source of data for this study came from semi-structured interviews. 16 interviews were conducted with experts and key actors in Iranian virtual higher education. In the interview protocol with eight questions, the following issues were addressed: quality in on campuses and VHE systems; components and contextual factors affecting VHE quality; strategies to promote virtual system evaluation; process and outcomes of quality in VHE. Interviews with the experts and key actors in Iranian VHE take between an hour and an hour and a half. Mention should be made that the ethical issues including privacy and confidentiality is taken into account in the study.

\section{Participants}

Theoretical sampling as "The process of selecting incidents, slices of life, time periods, or people on the basis of their potential manifestation or representation of important theoretical constructs" (Patton, 2001:238) is used for gathering data from rectors and policy makers of VHE; e-learning experts; and experts in quality of higher education especially in VHE (Strauss and Corbin, 1998). Interviews were continued until the data gathering 
achieved saturation. Theme saturation as Hyde (2003: 48) argues, "No new data are added because that category has been adequately explained".

Four groups of key actors in HE participated in this study including: five e-learning experts, researchers and university teachers who have had more than five year experience in doing research and teaching in e-learning and virtual education; three experts in the quality in higher education in general and two experts in quality of VHE who have focused on quality of virtual higher education; Six rectors and policy makers of VHE who have been in charge of establishing and administering of virtual higher education institutions. An outline of the participants is indicated in table 2.

Table 2. Participants in interview

\begin{tabular}{lc}
\hline Group interviews & $\begin{array}{c}\text { Number of } \\
\text { persons }\end{array}$ \\
\hline E-learning experts & 5 \\
Experts in the quality of HE and VHE & 5 \\
Directors and policy makers in VHE & 6 \\
\hline
\end{tabular}

Mention should be made that a majority of participants were engaged in teaching and learning activities in different virtual higher education institutions.

\section{Data Analysis}

The analysis of data in systematic approach grounded theory is done through open, axial and selective coding's (Strauss and Corbin, 1990). In the open coding, the data are usually broken down "into discrete parts, closely examined, compared for similarities and differences, and questions are asked about the phenomena reflected in the data" (Strauss \& Corbin, 1998: 102). Then, the extracted categories in process called "Axial coding" are connected to their subcategories. Lastly, the final level selective coding is accomplished in the process of "selecting the central or core category, systematically relating it to other categories, validating those relationships, and filling in categories that need further refinement and development" (Strauss and Corbin, 1990:116). To ensure the accuracy of the findings, the following activities were taken into account in the analysis of data collected (Creswell \& Miller, 2000).

\section{Member Checking}

The analysis and conclusions made based on the data collected were sent to the participants to verify that their understandings were accurately reflected in the analysis. Peer Examination: Four experts read and reanalyzed the transcribed interviews and made conclusions. Participatory Research: Simultaneous assistance of participants was received in the analysis and interpretation of data. Researcher Reflexivity: Addressing the possible prejudice and current prototypes, the researchers were tried to avoid such bias and prejudice. 


\section{Findings}

In this part findings of the study presented and discussed based on GT Strauss and Corbin paradigm model (1998). Informed by Glaser's approach (1992) the findings is presented in following three parts, "open", "axial" and "selective coding" (see figure 1).

\section{Open Coding}

During open coding, all of the transcribed interviews and extracted categories were examined and reexamined in a way that saturating occurred in every category. Fifteen categories were extracted, including Teaching-learning activities, key actors, Administrative factors, General context, Special context, Learning quality, University, Association level, Higher education level strategies, Higher education factors, Conceptual and Cultural factors, Macro factors, Individual output, Organizational results and upper organizational consequences. These categories had 32 subcategories and 173 basic concepts (live code) that represented multiple perspectives about the main categories (Creswell, 2012).

\section{Excerpt 1:}

... The main focus of higher education institutions activities is centered on teaching and learning process. It can be said that if these institutions could not promote students competences as it promised, it has practically failed. ...In the same way, students learning is a critical issue in virtual education. (G. $Y$ )

Key point: learning is seen as a core of educational system

Codes: learning hub of educational activities, learning instrument for achieving to functions of higher education, learning as pivotal in educational system at e-learning

\section{Memoing}

Memos as Glaser contends (1978: 83) are "theoretical notes about the data and the conceptual connections between categories written down as they strike the researcher". Memoing is considered a "core stage" or "the bedrock" of theory generation (Glaser, 1978). An example memo on "customized evaluation system for e- learning" is described below:

Information technologies provide a wide range of possibilities to enhance the learning and teaching procedure in universities. For instance, it provides unique opportunities to create, use and reuse learning resources which is not possible in face to face education. You can even record and present your lecturers in advance and discuss it in synchronize online sessions. These features provide great potential to enhance quality.

\section{Constant Comparison Method}

The codes arising out of each interview were constantly compared against the codes from the same interview, and those from other interviews and observations. This is GT's Constant Comparison Method (Glaser and Strauss 1967; Glaser 1992) which was used again to group these codes to produce a higher level of abstraction, called concepts in GT (see table 3). 
Table 3. Emergence of Category "human actors" from underlying concept

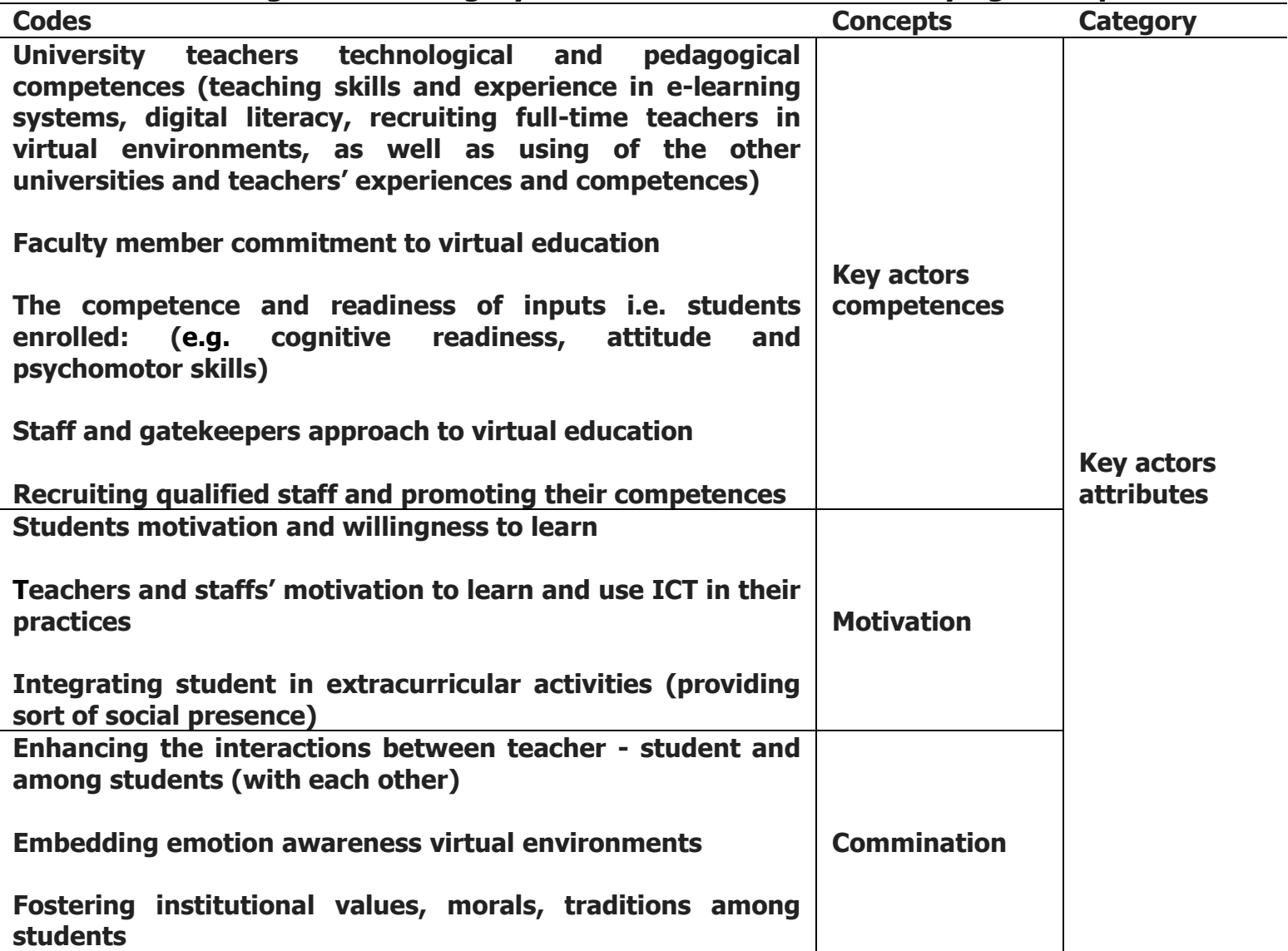

\section{Axial Coding}

In alignment with the Strauss and Corbin (1998) six categories model in axial coding, a paradigm was emerged out of the collected data. This paradigm comprises causal conditions, phenomenon, contexts, strategies, intervening conditions, and consequences. "Causal conditions" addresses events or activities that influence the phenomenon. "Strategies" refers to actions and interactions that is aimed and employed to resolve a problem, which, in turn, impacts on the phenomenon. "Contextual conditions" addresses a set of circumstances which events and actions are taken place within the given frame. "Intervening conditions" modify the impact of causal conditions on the phenomenon. "Consequences" refer to an action/interaction that is taken, resulting in a variety of different effects that may influence on the phenomenon (Hachtmann, 2012). According to the Strauss and Corbin's (1998) paradigm model when causal conditions occur and influence on the phenomenon, the context and intervening conditions inform the strategies that are used to bring about certain consequences.

\section{PARADIGM MODEL}

The categories' connections in this study are informed by Strauss and Corbin's (1998) paradigm model. The developed model and story is reflected in Figure 2. Based on paradigm model, detail of axial coding, concepts and categories are outlined in the following six categories. 


\section{Causal Conditions}

Causal factors that led directly to the quality of learning include three main categories:

1- Teaching and Learning Activities (Learning Process); 2- Key Actors' Attributes; and 3Administrative Issues.

Learning process that involves five sub-categories

Pedagogic approach; content production; management of learning interaction; interface design; and learning evaluation. Quality of learning results from optimized use of appropriately configured environments which are built from prudentially designed components and interfaces (Lindner, 2006).

Based on the data collected, teaching and learning process is the most important factor in shaping the quality of learning. This issue is reflected in other studies and e-quality frameworks (see Eexcellence benchmarking model, 2006; The SEEQUEL core quality framework, 2004; Distance Education and Training Council, 2012; Wu \& Lin, 2012; khan, 2005; Institute for higher education policy, 2009; Ossiannilsson \& Landgren, 2012; and Meier, Seufert \& Eule, 2012). The participants also emphasized on the importance of teaching - learning process, pedagogical issues, course and content development, assessment and evaluation, surface and interaction design in enhancing of e-learning quality. The following excerpts exemplifies the ways that the informants argue about learning quality:

Excerpt 2:

In designing and running courses in virtual contexts, interaction and quality of interaction between teacher and students and among students should be taken into account. Further, learning activities should be adopted based on students' individual differences. (M. D)

In the same way, A.M., another Informant, highlights that providing a digitalized version of learning recourses may not considered as e-learning by saying:

Excerpt 3:

.... Scanning and putting digitalized resources in the university's portal cannot be considered as e-learning. Interactions between teacher and students should be initiated in virtual environments. (A.M)

\section{Key actors' attributes}

This factor comprises three sub-categories including key actor's competencies, motivation and communications. These factor and sub-categories are highlighted in other studies and equality models (see Council for Higher Education Accreditation, 2002; Chen, 2009; Jung, 2010; Distance Education and Training Council, 2012; khan, 2005; Institute for higher education policy, 2000; Fresen, 2007; McKinnon, Walker \& Davis, 2000; and Bhuasiri, Xaymoungkhoun, Zo, Rho and Ciganek, 2012). Further, ICT support for teachers and students as well as pedagogical support for teachers are highly emphasized by the participants. In the following excerpt, A.S. highlights that the quality of inputs i.e. registered students in virtual programs:

\section{Excerpt 4:}

The quality of enrolled students in Iranian higher education settings is an important issue. Typically, in the entrance exam which is nationally conducted every year, students with higher scores choose main state universities ... and students with lowest score often ended up to virtual higher education institutions. Moreover, a large number of them are employee who would like to study along with their careers. (A. S) 
Administrative issues comprises following two sub-categories

Institutional support as well as management and leadership. Administrative issues' importance was highlighted in a large number of studies and models (see University of West Indies Distance Education Centre, 2006; Council for Higher Education Accreditation, 2002; Chen, 2009; Swedish National Agency for Higher Education, 2008; Masoumi, 2010; Distance Education and Training Council, 2012; khan, 2005; McKinnon, Walker \& Davis, 2000; Ossiannilsson \& Landgren, 2012; and Wu\& Lin, 2012). A.Z., one of the interviewed key actors, exemplifies the importance of administrative issues in general and students support in particular.

\section{Excerpt 5: \\ Continuous educational and technical support is vital in e-leaning program. Without such support dropout rate can be increased.... Student should feel that their needs are taken into account in no time! (A. Z)}

This except suggests that the virtual institutions strategies and activities should be articulated based on the students' needs and expectations.

Main Phenomenon (Core Category)

With a profound analysis of implementing interview text, it is verified that the "learning quality" is the main concern in virtual higher education institutions. Learning and teaching activities are key practices in educational settings, which are articulated differently in data collected such as "deep learning", "effective learning" and "value-added learning"; as well as "learning which can lead to entrepreneurship and employment". Learning is "...establishing new premises (i.e. paradigms, schemata, mental models, or perspectives) to override the existing ones" (Nonaka \& Takeucki, 1995). Cognitive and affective outcomes (Duque and Weeks, 2010) and degree of student understanding (Entwistle, 2000) are often seen as a sign of learning quality. Garrison and Anderson (2003) argue that learning quality is the most important factor in virtual institutions success. M.A., one of the interviewed experts, therefore argues that the students' learning process is the main phenomenon in higher education institutions.

Excerpt 6:

Higher educational institutions activities are mostly centered on students learning process. The institutions success also is usually measured with achieved competences, skills i.e. whit learning. This is very critical in virtual education; due to students usually pay for what they supposed to learn. (M.A.)

\section{Strategies}

Data suggested that it is hard to ignore human agents and institutional actors' roles in learning quality as the main phenomenon. The analysis of empirical data resulted in three key strategies for intervention, including: Micro or university level, mezzo or professional associations' level and macro or higher education ministry level. These actions/interactions facilitated the process leading up the main phenomena to consequences. The addressed strategies in this model are in accordance with the previous studies about the quality of higher education (see Belawati \& Zuhairi, 2007; and Harvey \& Williams, 2010).

\section{Excerpt 7:}

Quality assurance and quality enhancement can be undertaken in different levels. However, it seems that a semi-accreditation can suits most of the Iranian virtual higher education programs. (G.Y) 


\section{Excerpt 8:}

I think we need to have a quality control or evaluation department in each of virtual institutions. This can assure the quality of teaching and learning process. (N. M)

As indicated in excerpts 8, quality of learning as well as insuring and enhancing quality of learning is one of the main concerns of key actors in Iranian virtual higher education institutions.

Micro leve/ strategies are introduced with four practical approaches that are used inside the universities: setting indexes and criteria of quality; designing quality improvement model; applying quality assurance approaches; and using systematic approach.

Mezzo level emphasizes on creating a professional institute as national VHE accreditation association, which is overseeing the external quality evaluation.

Higher education level means strategies and policies that are adopted in macro or higher education ministry level for improving quality in VHE.

\section{Contextual Issues}

Contextual issues refer to the circumstances which shape and inform the quality of elearning. One of the interviewed experts, M.D., expresses an interesting aspect of how elearning can bring in a new approach to teaching and learning.

\section{Excerpt 9:}

E-learning and virtual education should be aligned with a new pedagogical culture e.g. learner-centered, problem-based, self-directed learning. In other words, we cannot use or replace our traditional way of teaching in virtual education.

In excerpt 9 another interviewed key actor argues that to enhance the quality of learning, teachers should shift their pedagogical approach, by saying:

Excerpt 10:

It seems that reciting and reproducing the transferred knowledge is highly encouraged by some of the teachers. Such approach simply doesn't fit with elearning..... (M.A.).

These contextual issues are identified and provided in two main categories including: General and Special contexts.

\section{General context}

As one of the contextual causes, include sub-categories of institutional culture; institutions willingness to change; and technological infrastructure. The given factors cover both the cultural-pedagogical infrastructure as well as technological infrastructures.

The importance of contextual issues particularly technological infrastructures are highlighted in other studies and frameworks (see: Chen, 2009; Fresen, 2007; Wu \& Li, 2012; Khan, 2005; 
Masoumi, 2010; Meier, Seufert \& Euler, 2012; Ossiannilsson \& Landgren, 2012, Khan, 2005; Masoumi, 2010; Meier, Seufert \& Euler, 2012; and The SEEQUEL core quality framework, 2004).

\section{Specific context}

The contextual feature address the ways that e-learning is carried out in Iranian higher educational institutions. This factor includes two sub-categories including e-learning models and specific features of e-learning.

Features of e-learning, such as the disaggregation of processes, the distance of students, distributed feature of teams (mixture of full and part time tutors) and openness to review make it different; therefore, the need for independent QA system is felt (Jara \& Mellar, 2009).

\section{Intervening Conditions}

Phenomenon of learning quality usually taken place in a certain circumstance. Environmental conditions mediate the process of main phenomenon through the strategies. In this study, circumstances include three main categories: Higher education factors; Intellectual and cultural factors; and Macro factors.

Higher education factors refer to policies, structures and established procedures in higher education institutions. E-learning is approached very differently in Iranian higher education institutions. This is highlighted in the following excerpt.

\section{Excerpt 11:}

In some higher education institutions, providing virtual education programs are centered in a center (as part of the main universities) while in some universities, virtual programs are provided by respected faculties. This informs the ways that e-learning can/should be carried out .... (M. A)

Organizational structure can be seen as a one of the main factor that informs the strategies and policies to improve the quality of e-learning (Jara \& Mellar, 2009).

\section{Cultural and cultural-pedagogical factors}

Cultural and cultural-pedagogical issues play an important role in shaping educational practices. They are embedded in a specific culture at different levels, from the individual level, the interpersonal level, to institutional, regional, and national levels. The cultural issues embrace following sub-categories: national culture; institutional culture, pedagogical values and norms such as the role of the teacher, the nature of the tasks, the ways of communicating and the ways technologies is embedded as well as the ways quality is defined.

Excerpt 12:

I think Iranian students and teachers' norms and preferences such as vocal culture should be taken into account in developing and conducting virtual courses. (M. D) 
The finding of the current study is in line with Shraim and Khlaif (2010) study that highlights the importance and role of culture as one of the main obstacles in success of e-learning in developing countries.

\section{Macro factors}

In an extracted paradigm, the macro factors include the political, economical and ethical issues which may influence on if and how e-learning should/could be implemented. The significance of macro factors is indicated in the following except (13).

For example, Zanjan University was one Iran's three pioneer universities in elearning.... But when the government changed, the university president was changed in 2006 and later the priorities were totally shifted. The new president of the University's announced "this educational approach (virtual education) is not our priority any longer". .... so organizational context is influential in everything .... (D. M)

Social, cultural, scientific, economic, political and administrative issues as well as the ways these issues are taken into account play a key role in shaping quality of higher education. The key role of contextual factors in designing and implemting e-learning is underlined in the Abdous conceptual model (2009). He concluded that accreditation, accountability, technology, economical pressures, students mobility, diploma mills, employer's needs, transnational education and competitiveness impact the process of quality assurance in elearning.

\section{CONSEQUENCES}

Outcomes in the developed model are outlined in three main categories including personal, organizational (effectiveness; and process of enhancement) and upper - organizational (e.g. issues such as internationalization and meeting societies needs and expectations). One of the interviewed experts, R.A., similarly exemplifies in excerpt 14 how organizational and upperorganizational issues can inform quality in e-learning.

\section{Excerpt 14:}

... Enhancing the scientific credibility as well as high employability can often be reflected in student's achieved skills and competences. These outcomes should be clearly indicated and followed in virtual institutions road map. (R. A)

The success (i.e. high learning quality) of virtual higher education can be indicated by a variety of criteria. York (1998) highlights the importance of responsibility; Harvey and Williams (2010) argue for employability; and Barrie and Ginns (2007) stress on getting more funding, as an indicator of the higher education quality. Udo, Bagchi, and Kirs (2011) address students' satisfactions and the extent of reaching learning objectives (loyalty, complaints, etc.) as learning quality. 


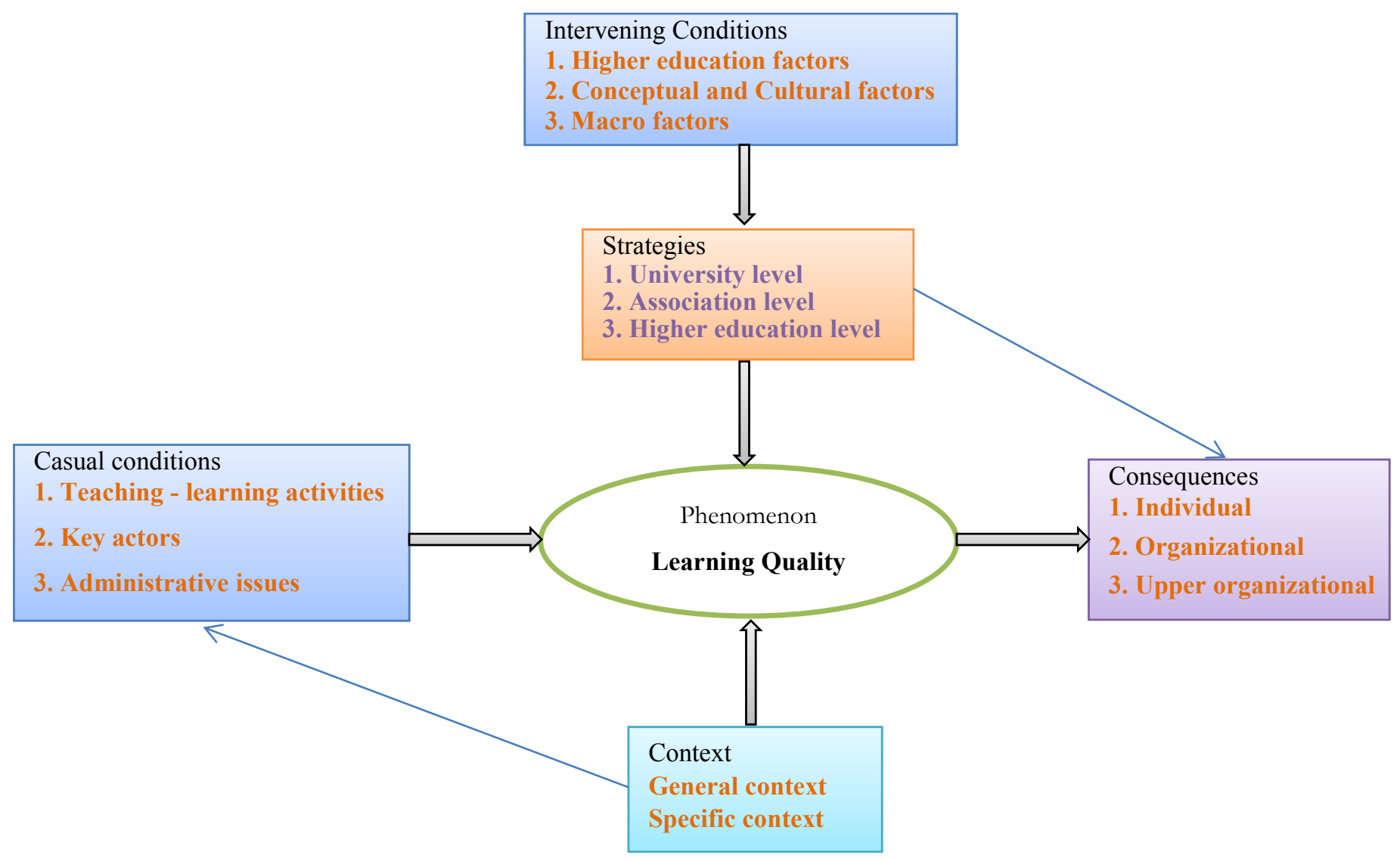

Figure 2. Paradigm model of quality improvement in virtual higher education

\section{Selective Coding}

Selective coding is the "process of integrating and refining the theory." Integration means that categories are interconnected and organized around a "central explanatory concept". The goal is to confirm those relations and to "fill in categories that need further refinement and development". Selective coding involved several steps. The first step was to recognize the core category by asking "what the research is all about" (Strauss \& Corbin, 1998, p. 146). At this stage researchers explored "learning quality" as core category and the central problem with which the interviewed and key actors are struggling. Finally, the following story is shaped.

\section{The Story}

The paradigm model developed as a result of this study suggests that learning process; competencies, motivation and communication of human actors; as well as administrative factors (casual conditions) alongside the general and special contexts constitute the learning quality (phenomenon). To enhance the quality of VHE, proper strategies should be developed at three levels i.e. micro, mezzo and macro. Developing such strategies in different levels cannot obviously be done without taking into account the Intervening Conditions issues i.e. Higher education factors, Cultural factors, and Macro contextual factors. The interactions between these factors can result in quality enhancement in virtual higher education. Mention should be made that learning quality in VHE has personal, organizational, and upperorganizational consequences. 


\section{Theoretical Propositions}

As a result of the paradigm model based on the collected data (see figure 2 and the story), a series of theoretical propositions were developed that can explain the ways that quality improvement process occurs in Iranian VHE.

$>$ Design, application and evaluation of teaching-learning activities, human and management factors are casual condition for improving learning quality in VHE.

$>$ University level, professional associations, and higher education institutions strategies are suitable strategies for improving learning quality in VHE.

$>$ General context (learning culture; key actors' willingness; educational context; and technological infrastructure) and specific context (e-learning models and specific features of e-learning) are producing special context for improving learning quality in VHE.

$>$ Higher education (structure and policies of higher education); Intellectual and cultural (national culture; institutional culture, pedagogical values and norms, the ways of communicating and the ways technologies is embedded); and Macro factors (political, economic, legal and ethical issues) as intervening conditions are producing situation for strategies to improve learning quality in VHE.

$>$ Improved learning quality has consequences such as individual outcomes, organizational outcomes (efficiency and effectiveness; and improvement of process) and upper - organizational outcomes (internationalization and meeting society's expectations).

\section{CONCLUSION}

The study aimed to explore the process of quality improvement in virtual higher education institutions in Iran and subsequently to develop a paradigm model to explain and enhance quality in virtual institutions. A grounded theory methodology is used to investigate quality improvement in Iranian virtual institutions. The developed paradigm model includes a variety of factors including: Learning process; competencies, motivation and interaction of key actors; and administrative factors with mediating role of the general and special contexts to create learning quality as a main issue. According to the findings, three levels of strategy i.e. micro, mezzo and macro are necessary for improving quality of learning in VHE. These strategies are informed by higher education environment. The interaction between these factors resulted in enhancing the quality of learning in VHE. The learning quality enhancement can have personal, organizational, and upper-organizational consequences.

The developed paradigm focuses on context, environmental intervention, strategies, outcomes and inter-relation among these factors that seems undermined in other studies (see; Wu \& Lin, 2012; Marshall, 2010; Ireland, Mary Correia \& Griffin, 2009; Abdous, 2009; Sung , Chang \& Yu, 2011; Jara \& Mellar, 2009; Ellis et al, 2007; Ossiannilsson \& Landgren, 2012; Thurab-Nkhosi \& Marshall, 2009; Jung, 2010; Udo, Bagchi \& Kirs, 2011; Fresen, 2007; CHEA, 2002; Chen, 2009). Unlike other e-quality models, the outlined model in this study has tried to provide a comprehensive picture of quality in virtual institutions, including casual condition, core issue, context, strategies, intervening factors, and subsequences. Having a procedural approach highlighted in model developed, learning process could be enhanced to meet the aims and expectations of the key actors in virtual institutions (quality improvement).

It should be noted that quality in higher education is a highly controversial concept with multiple meanings linked to how higher education is perceived (Tam, 2001). Future research 
may consider student perspectives about quality in VHE because "different stakeholder groups have different constraints, needs, and different motivations for using e-learning systems" (Bhuasiri, Xaymoungkhoun, Zo, Rho and Ciganek, 2012, p 852). The validation of the outlined model across countries in other developing countries may contribute to the literature. To address the quality in VHE, quality in traditional HE institution and its specific features should be investigated. The main question is do these two higher education system differ in paradigm or are they different only in delivery modes?

VHE in Iran and even in other developing countries is facing numerous challenges. By addressing enhancing and assuring quality as one the challenges in virtual higher education institutions, the model provided can be seen as a stepping stone to understanding quality dilemma. However, more studies and initiatives need to be done to promote VHE quality in Iran and other developing countries.

\section{BIODATA and CONTACT ADDRESSES of AUTHORS}

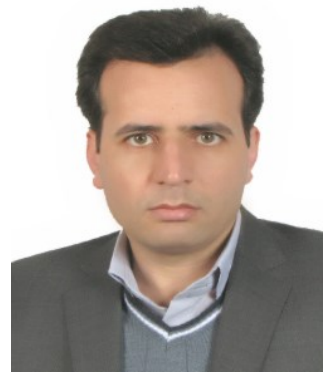

Rouhollah MAHDIUON is an Assistant Professor of educational administration at education and psychology Faculty in Azarbaijan Shahid Madani University. Dr. Rouhollah Mahdiuon gained his Ph.D. in Educational administration at Janurary, 2013. His academic interest areas are E- Learning and Virtual higher education, Quality in higher education, Mixed Method in Research, ICT integration in education and Social media use in education.

Rouhollah MAHDIUON

Azarbaijan Shahid Madani University

Department of Education

Education and Psychology Faculty

P.O.Box: 53714-161, Tabriz, Iran

Phone: +98-41-34327526

E-mail: rmahdiuon@gmail.com \& rmahdiuon@azaruniv.edu

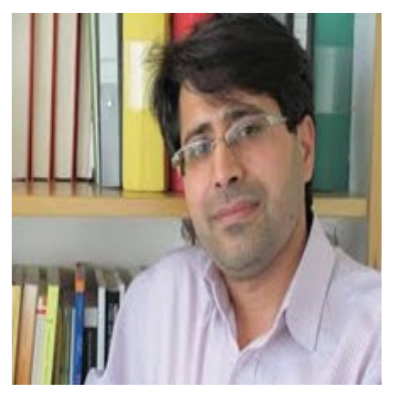

Davoud MASOUMI is a senior lecturer at the University of Gavle, Sweden and is affiliated with Aarhus University, Denmark. He conducts research and teaching in technology-mediated learning and the transformation of knowledge in contemporary society, both within the context of educational institutions and working life.

\section{Davoud MASOUMI}

University of Gavle, SE-801 76 Gavle, Sweden

Phone: +46 (0) 26648500

E-mail: Davoud.Masoumi@hig.se 


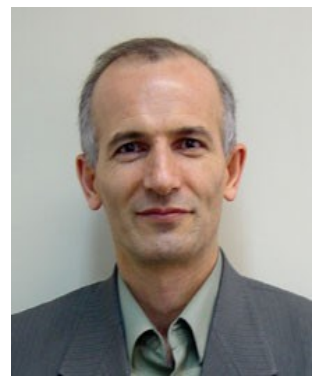

Maghsood FARASATKHAH is an Associate Professor of Higher Education Planning at Planning Department, Institute for Research and Planning in Higher Education, Iran. Dr Maghsood Farasatkhah gained his Ph.D. in Higher Education Planning at November, 2006. His academic interest areas are evaluation and accreditation in higher education, quality assurance, science studies, and qualitative research methods. He has over than 20 journal articles published in national and international journals. He is co-author of numerous journal articles. He has authored 15 books in Persian. Farasatkhah is the translator of a book in mixed method research from English to Farsi.

\section{Maghsood FARASATKHAH}

Planning Department, Institute for Research and

Planning in Higher Education (IRPHE).

No.70.Gholfam Ave, Nelson Mandela St. Tehran, Iran

Phone: ++98212200616

E-mail: m_farasatkhah@yahoo.com

\section{REFERENCES}

Abdous, M. (2009). E-learning quality assurance: A process-oriented lifecycle model. Quality Assurance in Education. 17 (3), 281-295.

Allen, I. E. \& Seaman, J. (2013). Changing course: Ten years of tracking online education in the United States. Babson Survey Research Group and Quahog Research Group, LLC. Retrieved Jun 15, 2016 from http://www.onlinelearningsurvey.com/reports/changingcourse.pdf

Anderson, J. \& McCormick, R. (2006). Pedagogic quality - supporting the next UK generation of elearning.secttion 26. In: Ehlers, U.D. \& Pawlowski, J. M. (2006). Handbook on quality and standardization in e-learning. (pp. 407-421). Berlin: Springer.

Australasian Council on Open, Distance and E-Learning (ACODE) (2007). ACODE benchmarks. Retrieved Oct 23, 2012, from http://www.acode.edu.au/benchmarks.php

Barat Dastjerdi, N. (2016). Quality in virtual education: the quality evaluation model for educational activities in virtual institutions. The Online Journal of Quality in Higher Education. 3 (1), 46-55.

Barrie, S. \& Ginns, P. (2007). The linking of national teaching performance indicators to improvements in teaching and learning in classrooms. Quality in Higher Education, 13(3), 275-286.

Belawati, T. \& Zuhairi, A. (2007). The Practice of a Quality Assurance System in Open and Distance Learning: A case study at Universitas Terbuka Indonesia (The Indonesia Open University). International Review of Research in Open and Distance Learning. 8(1), 1-15.

Bhuasiri, W., Xaymoungkhoun, O., Zo, H., Rho, J. J., \& Ciganek, A. P. (2012). Critical success factors for e-learning in developing countries: A comparative analysis between ICT experts and faculty. Computers \& Education, 58 (2), 843-855.

Brady, M. \& Loonam, J. (2010). Exploring the use of entity-relationship diagramming as a technique to support grounded theory inquiry, Qualitative Research in Organizations and Management: An International Journal, 5 (3), 224-237. 
Bunoti, S. (2011). The quality of higher education in developing countries needs professional support. Retrieved Dec 13, 2013, from http://www.intconfhighered.org/FINAL\%20Sarah\%20Bunoti.pdf

Chen, M. P. (2009). An Evaluation of the ELNP e-Learning Quality Assurance Program: Perspectives of Gap Analysis and Innovation Diffusion. Educational Technology \& Society.12 (1), 18-33.

Council for Higher Education Accreditation (2002). Glossary of Key Terms in Quality Assurance and Accreditation. Retrieved Jun 14, 2016, from http://www.uv.es/alfaacro/documentos/documentosinteres/29.htm

Creswell, J. and Miller, D. (2000). Determining validity in qualitative inquiry. Theory into Practice, 39(3), 124-130.

Creswell, J. W. (2012). Qualitative inquiry \& research design: choosing among five approaches. (3th ed). Thousand Oaks, Sage Publication.

Distance Education and Training Council (2012).DETC Accreditation Handbook. Retrieved July 3, 2014, from http://www.detc.org/accreditationhandbook/ 2012/2012_AC_handbook(100112).pdf

Dondi, C., Moretti, M., \& Nascimbeni, F. (2006). Quality of e-learning: Negotiating a strategy, implementing a policy. In: Ehlers, U. D. \& Pawlowski. J. M. (Eds.), Handbook on quality and standardization in e-learning (pp. 31-50). Berlin: Springer.

Duque, L. C. \& Weeks, J. R. (2010). Towards a model and methodology for assessing student learning outcomes and satisfaction. Quality Assurance in Education, 18 (2), 84 - 105.

Ehlers, U.D., Hildebrandt, B., Gqrtz, L. \& Pawlowski, J.M. (2005) Use and Distribution of Quality Approaches in European e-Learning, CEDEFOP, retrieved 1 March 2006, from http://www2.trainingvillage.gr/etv/publication/download/panorama/5162_en.pdf

Ellis, R. A. Jarkey, N. M., Mary J., Peat, M. \& Sheely, S. (2007). Managing quality improvement of eLearning in a large, campus-based university. Quality Assurance in Education. 15 (1), 923.

Entwistle, N. (2000). Promoting deep learning through teaching and assessment: conceptual frameworks and educational contexts. TLRP Conference, Leicester, November. retrieved 17 Jun 2016, from https: //innsida.ntnu.no/c/wiki/get_page_attachment?p_I_id=22780\&nodeId=24647\&ti tle $=$ Feedback +og + digital+feedback\&fileName $=$ Promoting\%20deep $\% 20$ learning\%20thr ough $\% 20$ teaching $\% 20$ and $\% 20$ assessment $\% 20$ conceptual\%20frameworks $\% 20$ and $\% 2$ Oeducational\%20contexts..pdf

European Association of Distance Teaching Universities (2006). E-xcellence. EADTU conference in Tallinn, Estonia, 23-24 November. Retrieved 17 Jun 2016, from http://www.eadtu.nl/excellencelabel/default.asp? mMid $=1$

Fresen, J. (2007). A taxonomy of factors to promote quality web-supported learning. International Journal on ELearning.6 (3), 351-362.

Garrett, R. (2004).The real story behind the failure of UK eUniversity. Edcause Quarterly, 27, 4, 2004. Retrieved 16 Jun 2016, from http://www.educause.edu/ero/article/real-storybehind-failure-uk-euniversity 
Garrison, D. R. \& Anderson T. (2003). E-Learning in the 21st Century. London and New York: Rutledge Falmer.

Giertz, B. (2001). Anything goes? The concept of quality revisited. Paper presented at The Sixth QHE Seminar, Birmingham, May 25-26. Retrieved 16 Jun 2016, from http://www.qualityresearchinternational.com/papers/giertz.pdf

Glaser, B (1978) Theoretical sensitivity: advances in the methodology of grounded theory. Sociology Press, Mill Valley, CA

Glaser, B (1992). Basics of grounded theory analysis: emergence vs forcing. Sociology Press, Mill Valley, CA

Glaser, B \& Strauss AL (1967). The discovery of grounded theory. Aldine, Chicago

Green, D. (1994). What is quality in higher education? Concepts, policies and practice. in Green, D. (Ed.), what is Quality in Higher Education? SRHE and Open University Press, Buckingham, 3-21.

Hachtmann, F. (2012). The process of general education reform from a faculty perspective: A grounded theory approach. The Journal of General Education, 61(1), 16-38.

Harvey, L. \& Green, D. (1993). Defining quality. Assessment and Evaluation in Higher Education. 18(1), 9-34.

Harvey, Lee \& Williams, James (2010). Fifteen Years of Quality in Higher Education, Quality in Higher Education, 16(1), 3-36.

Hoda, R., Noble, J. \& Marshall, S. (2011). Developing a grounded theory to explain the practices of self-organizing Agile teams. Empirical Software Engineering. 17, (6), 609-639.

Hyde, C.A. (2003). Multicultural organization development in nonprofit human service agencies: views from the field. Journal of Community Practice, 11(1), 39-59.

Inglis, A. (2005). Quality improvement, quality assurance, and benchmarking: comparing two frameworks for managing quality processes in open and distance learning. The International Review of Research in Open and Distance Learning. Retrieved 29 March 2009, from http://www.microsoft.com/isapi/ redir.dll?prd=ie\&pver= 6\&ar=CLinks

Iranian Higher Education Research and Planning Institute (2012).Statistic report. Tehran: Iranian Higher Education Research and Planning Institute (In Persian).

Ireland, J. Correia, H. Griffin, T.M. (2009). Developing quality in e-learning: a framework in three parts. Quality Assurance in Education. 17 (3), 250-263.

Jara M. and Mellar H. (2009). Factors affecting quality enhancement procedures for e-learning courses. Quality Assurance in Education. 17 (3), 220-232.

Jung, I. S., \& Latchem, C. (2007). Assuring quality in Asian open and distance learning. Open Learning, 22(3), 235-250.

Jung, I. (2011). The dimensions of e-learning quality: from the learner's perspective. Educational Technology Research and Development, 59(4), 445-464.

Khan, B. H. (2005). Managing e-learning: design, delivery, implementation and evaluation. Hershey, PA, Information Science Pub. 
Lindner, R. (2006). Architectures and frameworks. In: Ehlers, U.D. \& Pawlowski, J. M. (2006). Handbook on quality and standardization in e-learning. (pp: 193-208.). Berlin: Springer.

Liu, S. H., Liao, H. L., \& Pratt, J. A. (2009). Impact of media richness and flow on e-learning technology acceptance. Computers and Education, 52(3), 599-607.

Marshall, S. (2010). A Quality Framework for Continuous Improvement of e-Learning: The eLearning Maturity Model. Journal of Distance Education. 24(1), 143-166.

Masoumi, D. \& Lindstrom B. (2012). Quality in e-learning: a framework for promoting and assuring quality in virtual institutions. Journal of Computer Assisted Learning, 28(1), 2741.

Masoumi, D. (2010a). Quality in e-learning within a cultural context the case of Iran. Gothoburgen University, Göteborg, Sweden.

Masoumi, D. (2010b). E-learning in Iran: a breakthrough to ICT-based initiatives in an educational system. In: Demiray, Ugur (2010). Cases on challenges facing e-learning and national development: institutional studies and practices. Volume: I., (pp: 229-250). Anadolu University Eskisehir-Turkey.

McKinnon, K.R., Walker S.H. \& Davis D. (2000). Benchmarking: A Manual for Australian Universities. Dept. of Education, Training and Youth Affairs, Higher Education Division, Canberra. Retrieved 16 Jun 2016, from http://science.uniserve.edu.au/courses/benchmarking/benchmarking_manual.pdf

Meier, C., Seufert, S. \& Euler, D. (2012).Quality assessment and development in the course of the EFMD CEL programme accreditation. Journal of Computer Assisted Learning. 28(1), 5264.

Meyer A. K. (2006). The closing of the U.S. Open University. EDUCAUSE Quarterly, 29(2),5-7.

Nonaka, I. \& Takeucki, H. (1995). The Knowledge-Creating Company. Oxford University Press.

Oliver R. (2005). Quality assurance and e-learning: blue skies and pragmatism. Research in Learning Technology, 13(3), 173-187.

Ossiannilsson, E. \& Landgren, L. (2012). Quality in e-learning - a conceptual framework based on experiences from three international benchmarking projects. Journal of Computer Assisted Learning, 28(1), 42-51.

Patton, M.Q. (2001). Qualitative Research and Evaluation Methods (2th ed). Thousand oaks, CA: Sage Publications.

Pawlowski J.M. (2007) Quality mark e-learning: developing process- and product-oriented quality for learning, education and training. International Journal of Learning Technology .3(1), 51-71.

Reglin, T. (2006). E- Learning quality and standards from a business perspective. Handbook on quality and standardization in e-learning. Berlin, Springer.

Shraim, K., \& Khlaif, Z. (2010). An e-learning approach to secondary education in Palestine: opportunities and challenges. Information Technology for Development, 16(3), 159-173. 
Sloan Consortium (2010). Class differences: Online education in the United States. Retrieved Dec 08, 2010, from http://sloanconsortium.org/publications/survey/ pdf/class_differences.pdf.

Strauss, A. \& Corbin, J. (1998). Basics of qualitative research: Grounded theory procedures and technique. (2nd ed). Sage, Newbury Park, CA, London.

Strauss, A. and Corbin, L (1990). Basics of grounded theory methods. Beverly Hills, CA: Sage.

Sultan, P. \& Wong, H.Y. (2013). Antecedents and consequences of service quality in a higher education context: A qualitative research approach. Quality Assurance in Education, 21 (1), $70-95$.

Sung, Y.T., Chang, K. E. \& Yu, W.C. (2011). Evaluating the reliability and impact of a quality assurance system for E-learning courseware. Computers \& Education, 57(2), 1615-1627.

Sustainable Environment for the Evaluation of Quality in E-Learning (SEEQUEL) (2004). First published in 2004 by the MENON Network EEIG. Retrieved Oct 18, 2014, from http://www.menon.org/publications/TQM\%20Guide\%20for\%20informal\%20learning. pdf

Swedish National Agency for Higher Education (2008). E-learning quality: aspects and criteria for evaluation of e-learning in higher education [Report]. Stockholm: Swedish National Agency for Higher Education.

Tam, M. (2001). Measuring quality and performance in higher education. Quality in Higher Education, 7(1), 47-54.

The Institute for Higher Education Policy (2000). Quality on the line. Retrieved Jun 14, 2016, from http://www.nea.org/assets/docs/HE/QualityOnTheLine.pdf

Tucker, J P. \& Gentry, G R. (2009). Developing an e-learning strategy in higher education, Foresight. 11(2), 43-49.

Thurab-Nkhosi, D. \& Marshall, S. (2009). Quality management in course development and delivery at the University of the West Indies Distance Education Centre. Quality Assurance in Education. 17 (3), 264-280.

Udo, G. J., Bagchi, K. K. \& Kirs, P. J. (2011). Using SERVQUAL to assess the quality of e-learning experience. Computers in Human Behavior, 27(3), 1272-1283.

Wu, H.Y. \& Lin, H.Y. (2012). A hybrid approach to develop an analytical model for enhancing the service quality of e-learning. Computers \& Education. 58(4), 1318-1338.

Yorke, M. (1998). Performance indicators relating to student development: Can they be trusted?' Quality in Higher Education, 4(1), 45-61. 